\title{
Correction to: Zoonotic Disease Exposure Risk and Rabies Vaccination Among Wildlife Professionals
}

\author{
Sheena Tarrant, ${ }^{1}$ Jessie Grewal, ${ }^{1}$ Hayley Yaglom, ${ }^{1}$ Elisabeth Lawaczeck, ${ }^{1}$ \\ and Heather Venkat $\mathbb{D}^{1,2}$ \\ ${ }^{1}$ Centers for Disease Control and Prevention, Arizona Department of Health Services, $150 \mathrm{~N}$ 18th Ave Suite 140, Phoenix, AZ 85007 \\ ${ }^{2}$ Career Epidemiology Field Officer Program, Center for Preparedness and Response, Centers for Disease Control and Prevention, 1600 Clifton Rd, \\ Atlanta, GA 30333
}

Correction to: EcoHealth

$$
\text { https://doi.org/10.1007/s10393-020-01469-w }
$$

The original version of the article unfortunately contained a typo error in second author name in the author group. The author name was incorrectly published as "Jesse Grewal" and the correct name is "Jessie Grewal".

The original article can be found online at https://doi.org/10.1007/s10393-020-014 69-w.

Published online: March 19, 2020

Correspondence to: Heather Venkat, e-mail: hvenkat@cdc.gov 